\title{
Chartolepis intermedia Boiss. and Centaurea ruthenica Lam. - New Medicina Plants Containing Pharmacologically Active Compounds
}

\author{
Gaisha Mukhametzhanova*(D), Gulzina Asanova(D, Gulimzhan S. Adekenova, Balzhan Medeubayeva

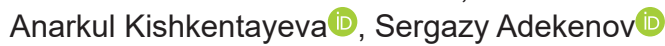

JSC International Research and Production Holding "Phytochemistry", Karaganda, Kazakhstan

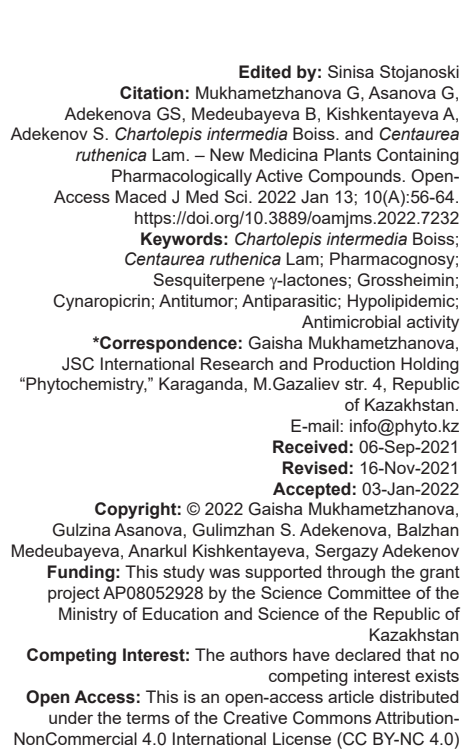

\section{Introduction}

Plants, as a renewable material, are a potential source of new natural compounds with a wide spectrum of pharmacological activity. Therefore, the main attention of researchers is directed to the search for new plant sources of pharmacologically active substances. Representatives of the genus Chartolepis Cass. and Centaurea L. are one of the promising medicinal plants. Genus Centaurea L. has more than 500 species, which are widespread in Europe, South and North America, and a large part of Asia. Twenty-seven species grow in Kazakhstan. According to the literature data, it is known that plants of the genus Centaurea L. contain phenolic compounds and sesquiterpene lactones. More than 200 sesquiterpene lactones were isolated and studied from 121 plant species of the genus
Centaurea L. [1], [2], [3]. There are nine known plant species of the genus Chartolepis Cass. [4]. From Chartolepis intermedia Boiss., Chartolepis glastifolia Cass., Chartolepis biebersteinii Jaub., and Chartolepis pterocaula (Trautv.) Czer., sesquiterpene lactones (grossheimin, cynaropicrin, centaurepensin, repin, cebelins C, D, and F, acroptyline, and janerin) were isolated and studied [5].

Grossheimin (1) is a sesquiterpene $\gamma$-lactone of guaian structure, which was isolated for the $1^{\text {st }}$ time in 1964 from Grossheimia macrocephala (Muss.-Puschk.) Sosn. et Takht., widely distributed in plants of the tribe CynareaeLess.:AmberboalippiDC., CentaureabehenL., Centaurea ruthenica Lam., Centaurea pseudomaculosa Dobrocz., Centaurea scabiosa L., Cynara scolymus L., Grossheimia glastifolia (L.) Cass., C. biebersteinii Jaub. et Spach., Ch. intermedia Boiss., C. pterocaula (Trautv.) Czer., (Muss.-Puschk.) Sosn. et Takht., and 
Grossheimia ossica (C. Koch.) Sosn. et Takht. [6], [7], [8], [9], [10], [11], [12], [13], [14], [15], [16], [17].

Cynaropicrin (2) was isolated for the $1^{\text {st }}$ time and described from Cynara scolymus L. [13]. Later, it was found in Grossheimia. macrocephala (Muss.Puschk.) Sosn. et Takht., Centaurea americana Nutt., C. behen L., Centaurea scoparia Sieber ex Spreng., C. scabiosa L., and Saussurea involucrata Kar. et Kir. and is contained in 24 plant species of the genus Saussurea DC. [13], [18], [19], [20], [21], [22].<smiles>C=C1C[C@@H](O)[C@H]2C(=C)C(=O)O[C@H]2[C@H]2[C@H](C)C(=O)C[C@H]12</smiles>

(1)<smiles>C=C(CO)C(=O)O[C@H]1CC(=C)[C@H]2C[C@H](O)C(=C)[C@H]2[C@H]2OC(=O)C(=C)[C@H]12</smiles>

(2)
According to the literature data, it is known that grossheimin (1) has an antitumor, anti-inflammatory effect, as well as cytotoxicity [14], and cynaropicrin (2) exhibits high cytotoxicity against leukemic cell lines, and also has an antispasmodic effect [23], [24], which indicates a wide range of pharmacological activity of plants of the genus Chartolepis Cass. and Centaurea L.

The most common plant species in the genus Chartolepis Cass. is Ch. intermedia Boiss. (Figure 1) Asteraceae family, which is a perennial plant found in the European part of Russia, in the south of West Siberia, in the northern and eastern parts of Central Asia [2], [3]. This species is widespread on the territory of Kazakhstan, the total operational reserve in the territory of Central Kazakhstan of dry aerial mass on an area of 5.3 hectares is 254.7 quintals with an annual harvest of 84.9 quintals [25].

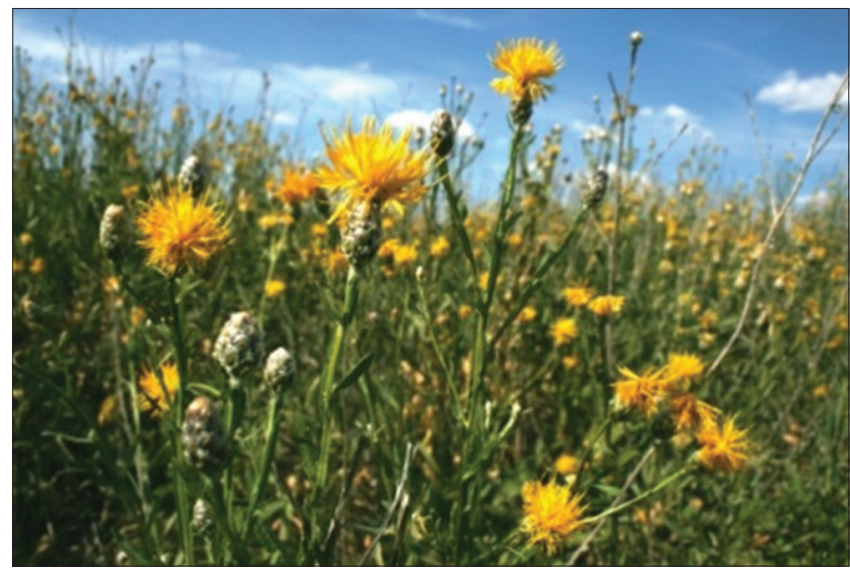

Figure 1: Chartolepis intermedia Boiss

In a comparative pharmacognostic study of plants of the genus Centaurea L., the most closely related to $\mathrm{Ch}$. intermedia Boiss. species is C. ruthenica Lam. (Figure 2) - perennial plant of the Asteraceae family, widespread in Southeast Europe, the Caucasus, Central Asia, Kazakhstan, Ural, and Altai [4].

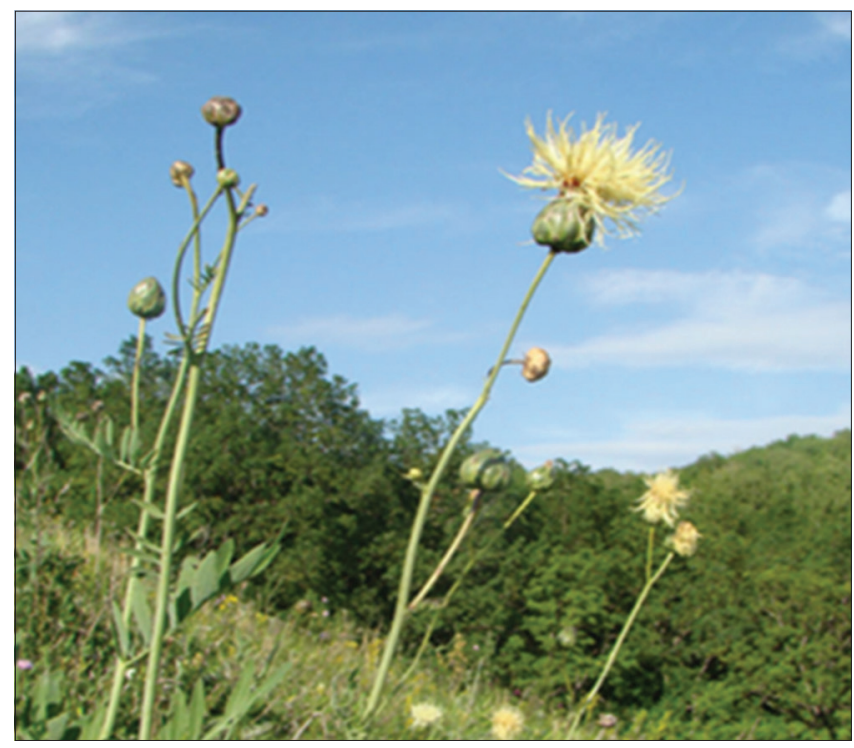

Figure 2: Centaurea ruthenica Lam

By morphological characteristics, Ch. intermedia Boiss. is close to $C$. ruthenica Lam. and both species belong to the tribe Cynareae Less. The literature contains mainly information on the morphology of the studied plant species, there are no data on their anatomical structure, therefore, the study of the anatomical and diagnostic features of Ch. intermedia Boiss. and C. ruthenica Lam. for the pharmacognosy of these types is relevant.

The purpose of this work is the chemical, morphological, and anatomical study of Ch. intermedia Boiss. and C. ruthenica Lam., determination of pharmacological activity to substantiate the possibility of using these plants as medicinal raw materials.

\section{Materials and Methods}

\section{Raw materials}

Aerial part (flower baskets and leaves) of Ch. intermedia Boiss. collected in the phases of rosette, budding in the vicinity of the village of Akbastau, Abay district, Karaganda region of the Republic of Kazakhstan.

Aerial part (baskets and leaves) of $C$. ruthenica Lam. collected in the flowering phase in the mountains of Chingiztau, Abay district of the East Kazakhstan region of the Republic of Kazakhstan.

Herbarium specimens are kept in the herbarium fund of JSC International Research and Production Holding "Phytochemistry" (KG) (Karaganda, Republic of Kazakhstan). 


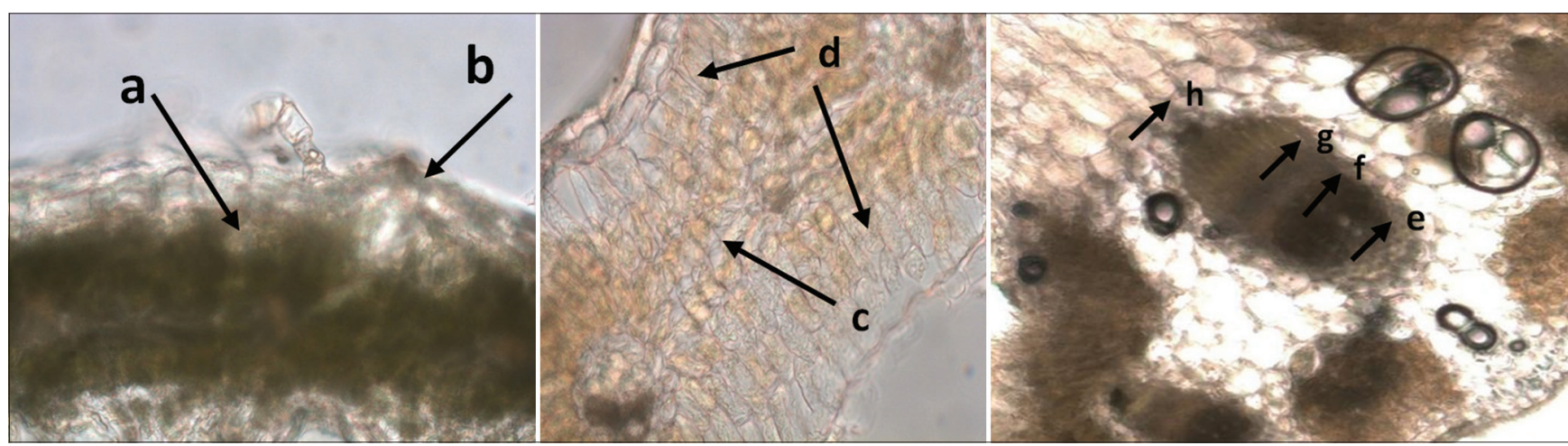

Figure 3: Cross-section of Chartolepis intermedia Boiss. leaf, (a) thick cuticle layer, (b) multicellular trichome, (c) spongy parenchyma, (d) palisade parenchyma, (e) xylem, (f) phloem, (g) collenchyma, and (h) sclerenchyma

\section{Microscopic analysis}

Dry samples of aerial organs of $\mathrm{Ch}$. intermedia Boiss. and C. ruthenica Lam. were soaked in hot water and softened in a mixture of glycerin-alcohol-distilled water in a ratio of 1:1:1 [26] (Strauss-Fleming reagent), boiled in a $5 \%$ aqueous solution of potassium hydroxide. Surface preparations and sections were made manually (Figure 3). Micropreparations were photographed using an Altamy Bio 8 scanning microscope (St. Petersburg, Russia) at a magnification of $16 \times 10,16 \times 20$, and $16 \times 40$. Figures were processed in Altami Studio and Paint.NET 4.2.8.

\section{Determination of acute and chronic toxicity}

The median lethal dose $\left(L_{50}\right)$ was determined by intragastric administration of the test substance to white outbred mice weighing 18-20 g. In total, 38 white mice were used in the experiment. Grossheimin (1) was injected into the stomach in the form of a $25-50 \%$ oil-alcohol emulsion $(0.2 \mathrm{ml}$ of ethyl alcohol was taken per $5 \mathrm{ml}$ of vegetable oil). The mice were monitored for 14 days. The experiment took into account the timing of death of animals, the clinic of poisoning, and macroscopic changes in the internal organs of dead mice. The data obtained were processed by known statistical methods.

\section{Extraction of raw materials and isolation of sesquiterpene lactones}

Extraction of Ch. intermedia Boiss. with ethyl acetate. $2.0 \mathrm{~kg}$ of aerial part (flower baskets and leaves) of $\mathrm{Ch}$. intermedia Boiss. was extracted with ethyl acetate at a temperature of $80^{\circ} \mathrm{C} 3$ times. After evaporation of the solvent, the resulting sum of extractive substances was treated with an alcohol-water mixture (2:1) at a temperature of $70^{\circ} \mathrm{C}$. The precipitate was separated by decantation, the filtrate was treated with chloroform. $86.8 \mathrm{~g}$ of the total extractive substances were chromatographed on a column with KSK silica gel at a sum-carrier ratio of 1:20.

Isolation of grossheimin (1). When the column was eluted with a mixture of petroleum ether ethyl acetate (4:1), $0.17 \%$ of compound (1) was isolated in terms of on the air-dry raw material.

Isolation of cynaropicrin (2). When the column was eluted with a mixture of petroleum ether: ethyl acetate (4:1), substance (2) was isolated with a yield of $0.22 \%$ in terms of the air-dry raw material.

Chloroform extraction of Ch. intermedia Boiss. and isolation of grossheimin (1). $11.0 \mathrm{~kg}$ of aerial part (flower baskets and leaves) of $\mathrm{Ch}$. intermedia Boiss. was extracted with chloroform at $45-50^{\circ} \mathrm{C}$ for $8 \mathrm{~h}$. After evaporation of the solvent, 365 sums of extractive substances were treated 3 times with an alcohol-water mixture $(2: 1)$ at a temperature of $70^{\circ} \mathrm{C}$. The precipitate was separated by decantation, the filtrate was treated with chloroform. Chloroform extracts were evaporated under vacuum and the resulting $180 \mathrm{~g}$ of the total of extractive substances was chromatographed on a column with aluminum oxide II degree of activity with the ratio of the sum-carrier $=1: 20$. When eluted with a mixture of benzene-ether (1:1), $14.85 \mathrm{~g}$ of compound (1) was isolated with a yield of $0.135 \%$ in terms of airdry raw material.

Chloroform extraction of C. ruthenica Lam. and isolation of grossheimin (1). $2.1 \mathrm{~kg}$ of leaves and flower baskets of $C$. ruthenica Lam. was exhaustively extracted with chloroform, after the extractant was evaporated under vacuum and $121.8 \mathrm{~g}$ of the total of extractive substances were obtained, which were subjected to aqueous-alcoholic treatment, the aqueous-alcoholic part was extracted 3 times with chloroform. After evaporation of chloroform under vacuum, the sum of extractive substances was obtained, which was chromatographed on a column with aluminum oxide (II degree of activity). When the column was eluted with a mixture of carbon tetrachloride and benzene (1:1), $1.6 \mathrm{~g}$ of compound (1) was isolated with a yield of $0.075 \%$ in terms of airdry raw material.

The composition of fractions and individual substances was monitored by thin-layer chromatography on Silufol plates using $0.5 \% \mathrm{KMnO}_{4}$ in $0.5 \% \mathrm{H}_{2} \mathrm{SO}_{4}$ as a developing agent, as well as using a ZF-20d ultraviolet analyzer at 254 and $365 \mathrm{~nm}$. 
For column adsorption chromatography, silica gel of the KSK brand and aluminum oxide (II degree of activity) was used. Melting points were determined using an OptiMelt apparatus (USA). The IR spectrum was recorded on "Avatar 360" spectrometer (USA) in tablets with potassium bromide in the range from 4000 to $500 \mathrm{~cm}^{-1}$. The specific optical rotation was measured on a "Polax-2L" semi-automatic polarimeter (Japan) in a tube $0.5 \mathrm{dm}$ in length and $3 \mathrm{ml}$ in volume. NMR spectra of the samples were recorded on a Jeol “JNM-ECA 500" spectrometer in $\mathrm{CDCl}_{3}$.

\section{Biological activity}

\section{Determination of antitumor activity}

The antitumor activity was studied on white outbred rats and mice using 12 strains of transplanted tumors. The antitumor effect was assessed with daily intraperitoneal injection of the substance in dimethyl sulfoxide for 10 days in the maximum tolerable dose (MTD). Treatment was started from the moment measurable tumor nodules appeared. At the end of the treatment, the animals were killed 1 day later. To assess the antitumor activity of the substance, the percentage of tumor growth inhibition was used, calculated by the mass of the hatched tumors in animals of the control and experimental groups (8-11 animals in each group). The data obtained were processed statistically.

\section{Determination of antiparasitic activity}

To reproduce the models of experimental opisthorchiasis, golden male hamsters (Mesocricetus auratus) of the SPF category, weighing 80-110 g, were used. Artificial infection of experimental animals with opisthorchiasis was carried out according to the method [27]. An anthelmintic drug with a broad spectrum of action "Praziquantel" was used as a reference drug. Reproduction of the model of experimental opisthorchiasis in vitro was carried out according to the generally accepted method [28].

\section{Determination of anthelmintic activity in dogs}

Experiments in vivo were carried out on pastoral dogs infested with various types of helminths. The average weight of the dogs was $10 \mathrm{~kg}$ and the average age was 12 months.

The reference drug was anthelmintic drug "CesTremForte," developed by the Kazakh Research Veterinary Institute (Almaty), the active ingredient of which is praziquantel. The effectiveness of the action of sesquiterpene lactones was determined according to the results of helminthicoprological and macrohelminthoscopic studies before and after dog dehelminthization.

\section{Determination of lipid-lowering activity}

The lipid-lowering activity was studied in experimental rats, which were injected into the stomach with grossheimin (1) and at a dose of $10 \mathrm{mg} / \mathrm{kg}$ for 7 days. The reference drug was nicotinic acid at a dose of $25 \mathrm{mg} / \mathrm{kg}$. Hyperlipidemia in rats was induced by a single intragastric administration of ethanol at a dose of $5 \mathrm{~g} / \mathrm{kg}$. In the blood serum of the tail vein, the content of triglycerides, total cholesterol, low- and high-density lipoprotein cholesterol, and free fatty acids was measured. The ratio of the content of high-density lipoprotein cholesterol to the amount of low-density lipoprotein cholesterol and the atherogenic index was calculated.

\section{Determination of antimicrobial activity}

The study of the antimicrobial activity of cynarpicrin was carried out in relation to the test strains of Gram-positive bacteria Staphylococcus aureus and Bacillus subtilis and Gram-negative strains of Escherichia coli and Pseudomonas aeruginosa by diffusion in agar (wells). The studied samples were dissolved in $96 \%$ ethyl alcohol at a concentration of $1 \mathrm{mg} / \mathrm{ml}$. Gentamicin was used as reference drug.

\section{Statistical processing of data}

The results obtained were processed statistically using the Student's test and using the Statistica 8.0 for Windows program. The critical level of significance when testing statistical hypotheses was taken equal to 0.05 [28].

\section{Results and Discussion}

The choice of the direction of research is due to the chemosystematic relationship of plant species Ch. intermedia Boiss. and C. ruthenica Lam., the main components of which are the pharmacologically active sesquiterpene lactones grossheimin (1) and cynaropicrin (2). Therefore, the studied plant species can be considered as new potential sources of original anticancer, antimicrobial, and antiparasitic preparations.

Ch. intermedia Boiss. is a plant $40-100 \mathrm{~cm}$ tall; stem erect, finely ribbed; leaves are petiolate, venation is pinnate, leaf shape is elliptical-obverse-lanceolate to almost lanceolate, there are hairs and glands; the tip of the leaf is pointed; multi-row phyllaries; flowers are yellow; pappus is pinnated, muddy-smoky.

Cells of epidermis covered with a thick cuticle layer; the mesophyll consists of several rows of palisade cells located on both sides of the spongy parenchyma, that is, it has an isolateral palisade type of structure; there are multicellular trichomes. The cross-section 
of the leaf also clearly shows the structure of the conducting bundle, consisting of phloem and xylem, belongs to the collateral type of structure. The stomata are randomly located on the upper and lower sides of the leaf. Ch. intermedia Boiss. is characterized by an anomocytic type of stomata arrangement. Biologically active substances are localized in the area of the spongy mesophyll or under the conducting bundles of the leaf and around the conducting bundles of the stem.

When looking at a leaf cross section of C. ruthenica Lam., it can be noted that the conceptacles are located in the peripheral zone (Figure 4a).

Leaf of C. ruthenica Lam. on a cross-section has an isolateral structure, that is, the columnar mesophyll is located on both sides of the leaf blade. The top surface of the leaf is smoother, while the bottom has a folded structure. The cross-section shows simple 2-3 cell trichomes, which are located only on the upper epidermis. The conceptacles on the cross-section are round or oval, colored in dark brown colors, located in the area of the spongy mesophyll or under the conducting bundles. The central and lateral conducting bundles are collateral closed (Figure 4b).

Epidermis of phyllaries of C. ruthenica Lam. consists of elongated (prosenchymal) cells lined with long, reddish-brown areas of conceptacles (Figure 4c).

To distinguish Ch. intermedia Boiss. from C. ruthenica Lam., we compared their anatomical and diagnostic features. It was established that $\mathrm{Ch}$. intermedia Boiss. leaf type is isolateral-palisade, mesophyll consists of several rows of palisade cells and spongy parenchyma, epidermal cells are straight-walled elongated, cells of the lower epidermis are small, densely located, in the epidermal cells of the stem there are small deeply seated glands. The conceptacles are located in the area of the spongy mesophyll or under the conducting bundles of the leaf, around the conducting bundles of the stem and the epidermis of phyllaries.

Unlike Ch. intermedia Boiss., in C. ruthenica Lam., the type of the leaf is isolateral, the mesophyll is differentiated into columnar and spongy tissues, the epidermal cells of the upper epidermis are tortuous walled, the lower epidermis is weakly tortuous walled, the conceptacles are oblong, located in the peripheral part of the leaf and in phyllaries.

The main indicator of the quality of medicinal plant raw materials is the content of biologically active substances in it.

Since Ch. intermedia Boiss. and C. ruthenica Lam. are close in botanical description, we studied the indicated plant species for the content of sesquiterpene $\gamma$-lactones.

To extract grossheimin (1) and cynaropicrin (2), an ethyl acetate extraction of the aerial part (flower baskets and leaves) of $\mathrm{Ch}$. intermedia Boiss. was carried out. The raw material was extracted 3 times with ethyl acetate at a temperature of $80^{\circ} \mathrm{C}$, the resulting sum of extractive substances was subjected to water-alcohol treatment followed by extraction with chloroform. The chloroform extract was evaporated under vacuum and chromatographed on a KSK silica gel column at a sumcarrier ratio $(1: 20)$, eluting with a mixture of petroleum ether: ethyl acetate (4:1), a colorless crystalline substance (1) of the composition $\mathrm{C}_{15} \mathrm{H}_{18} \mathrm{O}_{4}$ was isolated, m.p. $200-202^{\circ} \mathrm{C}$ (ethanol), $[\alpha]^{20} \mathrm{D}+159.9^{\circ}$ (c 1.15; chloroform). The yield of (1) was $0.17 \%$ in terms of airdry raw materials.

According to physicochemical constants, infrared (IR)- and ${ }^{13} \mathrm{C}$-nuclear magnetic resonances $\left({ }^{13} \mathrm{C}\right.$ NMR) spectra and comparison with literature data [12], the isolated compound was identified as sesquiterpene lactone grossheimin (1).

Further elution of the column with a mixture of petroleum ether: ethyl acetate (4:1) gave a light brown oily substance (2), composition $\mathrm{C}_{19} \mathrm{H}_{22} \mathrm{O}_{6}$, $[\alpha]^{20} D+108.6^{\circ}$ (c 1.19; alcohol). Yield of (2) was $0.22 \%$ in terms of air-dry raw materials.

According to the results of spectral data (IR-, PMR-, and ${ }^{13} \mathrm{C}-\mathrm{NMR}$ ) and comparison with the available literature data [12], the isolated compound was identified as the sesquiterpene lactone cynaropicrin (2).

It is known that the biosynthesis of sesquiterpene lactones in plants is carried out by

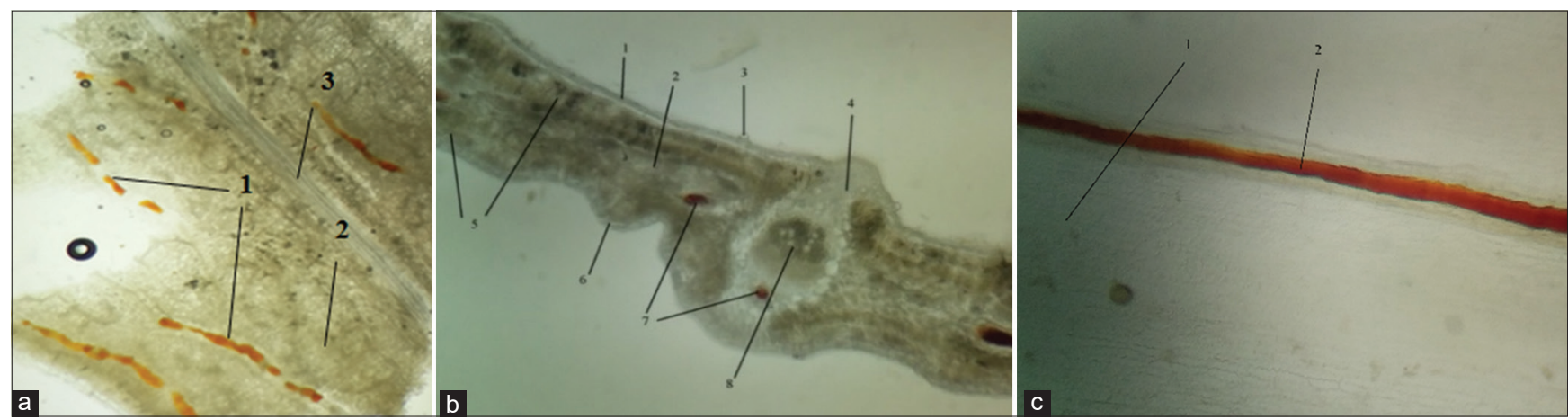

Figure 4: Localization sites of biologically active substances on anatomical cross sections of Centaurea ruthenica Lam. (16 $\times$ 10 mag.) (a) surface preparation, (1) conceptacles, (2) spongy mesophyll, (3) vein; (b) cross-section of a leaf (side section) (1) upper epidermis, (2) spongy mesophyll, (3) trichome vestige, (4) collenchyma, (5) columnar mesophyll, (6) lower epidermis, (7) conceptacles, (8) xylem; (c) preparation of phyllary (1) main cells of epidermis, (2) conceptacles 
specialized chloroplasts, which are localized mainly in the cells of glandular trichomes, parenchymal cells of the mesophyll, sclerenchyma tissues, in the xylem and conducting bundles of the leaf, as well as in the wraps of flower baskets and are able to accumulate in intracellular conceptacles - idioblasts.

We studied the dynamics of accumulation of sesquiterpene lactones in individual organs of Ch. intermedia Boiss. by phases of vegetation of the plant (Table 1).

Table 1: The content of grossheimin (1) in the organs of Chartolepis intermedia Boiss. by phases of plant vegetation

\begin{tabular}{lll}
\hline $\begin{array}{l}\text { Phenophases and } \\
\text { plant organs }\end{array}$ & Type of extraction & $\begin{array}{l}\text { The yield of grossheimin (1), } \\
\text { in \% for air-dry raw materials }\end{array}$ \\
\hline $\begin{array}{l}\text { Rosette phase } \\
\text { Leaves }\end{array}$ & Chloroform & 0.28 \\
$\begin{array}{l}\text { Budding phase } \\
\text { Leaves }\end{array}$ & Chloroform & 0.24 \\
& Chloroform at $50^{\circ} \mathrm{C}$ & 0.35 \\
Stems & Chloroform & 0.06 \\
$\quad$ Flower baskets & & 0.08 \\
Flowering phase & Chloroform & 0.18 \\
Leaves & & 0.04 \\
Stems & & 0.03 \\
Flower baskets & & \\
\hline
\end{tabular}

As can be seen from the table, the quantitative content of grossheimin (1) is localized in the leaves of $\mathrm{Ch}$. intermedia Boiss. both in the rosette phase and in the budding and flowering phase. In this case, the quantitative yield of grossheimin (1) depends on the extraction temperature. Hence, when the leaves collected in the budding phase are extracted with chloroform at $50^{\circ} \mathrm{C}$, the yield of grossheimin (1) is $0.14 \%$ based on air-dry raw materials.

Grossheimin (1) is found in all organs of $\mathrm{Ch}$. intermedia Boiss., except for the roots. Its quantitative content was found in rosette leaves collected in the rosette phase and in stem leaves in the budding phase. During the flowering period, the content of grossheimin in the leaves decreases. The completeness of the extraction of grossheimin (1) from rosette and stem leaves depends on the extractant (Table 1).

As shown from Table 1, for the preparative isolation of grossheimin (1) from Ch. intermedia Boiss., it is rational to use air-dried leaves and buds of $\mathrm{Ch}$. intermedia Boiss., collected during phases of rosette and budding.

The technology for the isolation of grossheimin (1) and cynaropicrin (2) was optimized, which consists in the extraction of $\mathrm{Ch}$. intermedia Boiss. raw material with an ethanol: water (1:1) mixture under the action of ultrasound at a temperature of $20-22^{\circ} \mathrm{C}$ for $90 \mathrm{~min}$ [29].

According to the results of the HPLC analysis, the extraction of $\mathrm{Ch}$. intermedia Boiss. raw material with a mixture of ethanol: water (1:1) under the action of ultrasound provides a quantitative yield of grossheimin (1) up to $8.22 \%$ and cynaropicrin (2) up to $24.27 \%$ (Table 2). Ultrasound creates acoustic cavitation in the extractant, which contributes to the destruction of the cell walls of plant raw materials, increasing the diffusion of the solvent into the plant cell, which leads to a rapid transition of biologically active components into the extract.
Table 2: HPLC analysis data on the content of grossheimin (1) and cynaropicrin (2) in extracts

\begin{tabular}{lllll}
\hline № & Extractant & $\begin{array}{l}\text { Extraction } \\
\text { time }\end{array}$ & $\begin{array}{l}\text { Content of } \\
\text { grossheimin (1),\% }\end{array}$ & $\begin{array}{l}\text { Content of } \\
\text { cynaropicrin (2), \% }\end{array}$ \\
\hline 1 & Ethanol & $30 \mathrm{~min}$ & 5.25 & 19.4 \\
2 & Ethanol & $60 \mathrm{~min}$ & 6.84 & 20.27 \\
3 & Ethanol & $90 \mathrm{~min}$ & 4.74 & 15.38 \\
4 & Ethanol: water (1:1) & $30 \mathrm{~min}$ & 6.06 & 16.1 \\
5 & Ethanol: water (1:1) & $60 \mathrm{~min}$ & 7.70 & 22.4 \\
6 & Ethanol: water (1:1) & $90 \mathrm{~min}$ & 8.22 & 24.27 \\
7 & Ethanol: water (1:1) & $120 \mathrm{~min}$ & 8.20 & 18.7 \\
8 & Ethanol: water (1:1) & $150 \mathrm{~min}$ & -- & 17.18 \\
\hline
\end{tabular}

From flower baskets and leaves of $C$. ruthenica Lam. by chloroform extraction followed by chromatography of the isolated sums of extractive substances on a column with aluminum oxide (II degree of activity), a crystalline substance of the composition $\mathrm{C}_{15} \mathrm{H}_{18} \mathrm{O}_{4}$ was isolated, identified by physicochemical constants and spectral data (IR-, PMR-, and $\mathrm{C}^{13}$-NMR) as grossheimin (1). Yield of (1) is $0.075 \%$ in terms of air-dry raw materials.

Lack of cynaropicrin (2) in C. ruthenica Lam. a closely related species to $\mathrm{Ch}$. intermedia Boiss. indicates that in C. ruthenica Lam. only grossheimin biosynthesis takes place (1)

The introduction of a new medicinal plant into medical practice is impossible without a preliminary assessment of its safety. Therefore, we carried out an experimental study of acute and chronic toxicity of grossheimin (1) from C. ruthenica Lam. and Ch. intermedia Boiss.

To justify the use of Ch. intermedia Boiss. and C. ruthenica Lam. as a new medicinal plant raw material, we carried out the study of pharmacological activity of sesquiterpene lactones (1) and (2).

\section{Acute and chronic toxicity of grossheimin (1)}

According to the results of the study of acute toxicity, it was established that grossheimin (1) belongs to the category of moderately toxic substances. The $\mathrm{LD}_{50}$ of grossheimin (1) with a single intraperitoneal injection to laboratory rats is $740-800 \mathrm{mg} / \mathrm{kg}$. At doses of 900 and $1000 \mathrm{mg} / \mathrm{kg}$, a depressing effect was noted, the animals died on the 1-2 days after exposure to the substance in a state of depression from respiratory arrest. Autopsy of dead animals revealed microscopic blood flow of internal organs.

According to the results of a study of chronic toxicity, grossheimin (1) showed that its administration at a dose of $80-90 \mathrm{mg} / \mathrm{kg}$ to laboratory rats and mice for 10 days did not cause pathological changes in the general condition of the animals. Autopsy of the rats and mice killed at the end of the experiment showed a mild plethora of internal organs.

\section{Antitumor activity of grossheimin (1)}

When studying the antitumor activity of grossheimin (1) on 12 strains of transplanted tumors 
(Pliss lymphosarcoma, Walker's carcinosarcoma, Guerin's carcinoma, sarcoma 45, M-1 sarcoma, breast cancer PMK-1, solid Ehrlich tumor, alveolar cancer of the liver PC-1, sarcoma 37 , sarcoma 180 , leukemia $\mathrm{P}-388$, and leukemia L-1210), it was revealed that (1) in the MTD $(90 \mathrm{mg} / \mathrm{kg})$ significantly inhibited the growth of sarcoma 180 (by $96.2 \% ; P<0.05$; at a dose $30 \mathrm{mg} / \mathrm{kg}$ by $56.7 \%$; $P<0.05$ ), Pliss Iymphosarcoma (by $84.4 \% ; P<0.05$ ), and solid Ehrlich tumor (by $77.8 \% ; P<0.05)$.

\section{Lipid-lowering activity of grossheimin (1)}

A single administration of ethanol in the blood serum of experimental rats increased the level of triacylglycerides by 1.9 times, free fatty acids by 3.2 times, and cholesterol in low-density lipoproteins - by $44 \%$ compared with the indices of intact animals. This indicates the development of acute hyperlipidemia. Serum total cholesterol, high-density lipoprotein cholesterol, and atherogenic index did not change.

The course administration of grossheimin (1) in acute hyperlipidemia was accompanied by a decrease in the serum level of triacylglycerides by $19.8 \%$, respectively. Nicotinic acid reduced the content of triacylglycerides by $42.4 \%$. Grossheimin (1) and nicotinic acid reduced the elevated level of free fatty acids in the blood serum of rats by 60.7-67.9\%. In acute hyperlipidemia, grossheimin (1) lowered the level of cholesterol in low-density lipoproteins by $17.6-20 \%$, and nicotinic acid by $15.7 \%$, and nicotinic acid did not alter the content of cholesterol in high-density lipoproteins. With the course administration of grossheimin (1) and nicotinic acid, the ratio of cholesterol in high-density lipoproteins to the amount of cholesterol in lowdensity lipoproteins significantly increased by $42.8 \%$ and $22.1 \%$, respectively.

According to the results of experiments, it was established that grossheimin (1) has a hypolipidemic effect in acute experimental hyperlipidemia caused by the introduction of ethanol, normalizes lipid metabolism, reduces the content of triacylglycerides, total cholesterol, and LDL cholesterol in the blood serum, and reduces the level of free fatty acids.

\section{Antimicrobial activity of cynaropicrin (2)}

The study of the antimicrobial activity of cynaropicrin (2) showed a pronounced antibacterial activity against both the Gram-positive bacteria $S$. aureus and $B$. subtilis, and against the Gramnegative bacteria $E$. coli and $P$. aeruginosa. According to the results of biological screening, it was determined that the minimum bacteriostatic concentration of the test substance $(2)$ is $0.1 \mu \mathrm{l}$.

\section{Antiparasitic activity of grossheimin (1) and cynaropicrin (2)}

As a result of a study of the anti-opisthorchiasis activity of grossheimin (1) and cynaropicrin (2) at a concentration of $10 \mu \mathrm{M}$ using tests for the mobility of the marita Opisthorchis felineus, it was established that $5 \mathrm{~min}$ after treatment, the studied samples caused immobilization of the helminths. At the same time, under the influence of grossheimin (1), the worms showed an indicative dynamics of a decrease in mobility, starting from $48 \mathrm{~h}$. The minimum mobility of helminths was observed 6 days after the start of the treatment of maritas with the tested samples (1) and (2) and amounted to 1.2-1.3 points, which indicates an almost complete immobilization of the helminths.

According to the results of tests on the survival of adult $O$. felineus worms, it was established that grossheimin (1) and cynaropicrin (2) have the effect of reducing the survival of helminths after incubation for 6 days at a concentration of $10 \mu \mathrm{M}$.

In a day, grossheimin (1) and cynaropicrin (2) at a concentration of $50 \mu \mathrm{M}$ were shown to damage the tegument of opisthorchids $O$. felineus, that is, the ability to damage the shell of helminths was revealed, which leads to their inevitable death.

The anthelmintic efficacy of cynaropicrin (2) was studied on the model of acute, chronic, and superinvasive opisthorchiasis and in the residual period of the disease in Syrian hamsters. High anthelmintic anti-opisthorchiasis activity of cynaropicrin (2) in chronic and superinvasive forms was revealed, pathological changes in the liver were traced before and after complete dehelminthization. Cynaropicrin (2) did not cause apoptosis of cells, dystrophic, necrobiotic, and necrotic processes of hepatocytes, the preparation did not induce proliferative reactions of the elements of the stroma and liver parenchyma, did not have a nephrotoxic effect.

Under in vitro conditions, it was established that under the action of grossheimin (1) and cynaropicrin (2), the survival and mobility of helminths decrease, the tegument of $O$. felineus was damaged, which led to the inevitable death of helminths.

When studying the efficacy of the sesquiterpene lactone cynaropicrin (2) against helminths in vivo, no side effects were revealed in the animals under study. 7-10 days after treatment, a coproovoscopy of feces was performed to determine the extension and intensity efficacy of cynaropicrin (2). The extensibility of cynaropicrin (2) was $41.67 \%$, the intensity was $88.62 \%$. In conditions on dogs, cynaropicrin (2) showed $100 \%$ effectiveness in case of tapeworm infection (Taenia sp.). 


\section{Conclusion}

The obtained experimental data on the pharmacological activity of the sesquiterpene lactones grossheimin (1) and cynaropicrin (2) allow considering Ch. intermedia Boiss. and C. ruthenica Lam. new medicinal plants that are of interest as promising sources for the development of original antiparasitic and antitumor drugs.

The results obtained on the methods for the isolation of sesquiterpene lactones make it possible to develop technologies for the production of new drug substances based on grossheimin (1) and cynaropicrin (2), which have antitumor, antiparasitic, hypolipidemic, and antimicrobial activity.

According to the results of anatomical and diagnostic studies, it was revealed that the distinctive features of $\mathrm{Ch}$. intermedia Boiss. are epidermal cells of a straight-walled elongated shape and in C. ruthenica Lam. - tortuous-walled. The revealed diagnostic features allow to identify and standardize the studied medicinal plants.

It was determined that Ch. intermedia Boiss. is the main source of sesquiterpene $\gamma$-lactones grossheimin (1) and cynaropicrin (2). At the same time, it was revealed that the quantitative yield of (1) and (2) from aerial part of $\mathrm{Ch}$. intermedia Boiss. is provided by extraction with a mixture of ethanol: water (1:1) under the action of ultrasound. When studying the dynamics of localization of sesquiterpene lactones in individual organs of $\mathrm{Ch}$. intermedia Boiss. depending on the vegetation phase of the plant, it was revealed that grossheimin (1) is localized mainly in the leaves and buds in the rosette and budding phases of the plant.

\section{References}

1. Plant Resources of the USSR. Flowering Plants, their Chemical Composition, Use. Family Asteraceae Sokolov P.D. St. Petersburg, Science; 1993. p. 350.

2. Pavlov NV. Flora of Kazakhstan. Vol. 9. Alma-Ata: Science; 1966. p. 420.

3. Bruno M, Bancheva S, Rosselli S, Maggio A. Sesquiterpenoids in subtribe Centaureinae (Cass.) Dumort (tribe Cardueae, Asteraceae): Distribution, 13C NMR spectral data and biological properties. Phytochemistry. 2013;95:13-95. https:// doi.org/10.1016/j.phytochem.2013.07.002. PMid:23948259

4. Cherepanov SK. Chartolepis Genus-Chartolepis Cass Flora of USSR. Vol. 28. Moscow: Science; 1963. p. 335-40.

5. Nowak G, Drożdż B, Holub M. Sesquiterpene lactones. $32^{\text {nd }}$ Guaianolides in species from the genus Chartolepis Cass. Acta Soc Bot Pol. 1986;55(2):233-8. https://doi.org/10.5586/ asbp.1986.052

6. Rybalko KS, Bankovsky Al, Kibalchich PN. Grossheimin is a new sesquiterpene lactone from Grossheimia macrocephala (Muss.Puschk.) Sosn. et Takht. J Gen Chem. 1964;34(4):580-4.

7. Fraga BM. Natural sesquiterpenoids. J Nat Prod Reports 1985;4:147-61.

8. Sulsen V, Martino V. Sesquiterpene Lactones. Advances in their Chemistry and Biological Aspects. Cham, Switzerland: Springer International Publishing AG; 2018. p. 381.

9. Rybalko KS. Natural Sesquiterpene Lactones. Moscow: Medicine; 1978. p. 320.

10. Fischer NM, Olivier TJ, Fischer HD. The biogenesis and chemistry of sesquiterpene lactones. Fortschr Chem Org Nat. 1979;38:47-390

11. Seaman FC. Sesquiterpene lactones as taxonomic characters in the Asteraceae. Bot Rev. 1982;48(2):121-594. https://doi. org/10.1007/BF02919190

12. Adekenov SM, Kagarlitsky AD, Kupriyanov AN. Sesquiterpene lactones of Central Kazakhstan, Alma Ata: Science; 1987. p. 240.

13. Samek Z, Holub M. Sesquiterpene lactones of Cynara scolymus L. Species. Tetrahedron Lett. 1971;50:4775-8.

14. Samek Z, Holub M, Vokáč K, Drożdż B, Jommi G, Gariboldi P et al. On terpenes. CCXIX. The structure of grosheimin. Coll Czec Chem Commun. 1972;37(8):2611-29. https://doi. org/10.1135/cccc19722611

15. Gonzales AG, Marrero BG, Breton JL. de las Compuestas XT Estructura de la grosshemina, lipidiol, e isolipidiol. Lactonas de la a lippi DC Y SU possible estereoqumica. An Quim. 1970;66:799-813.

16. Rustaiyan A, Niknejad A, Zdero C, Bohlmann F. A guaianolide from Centaurea behen. Phytochemistry. 1981;20(10):2427-9. https://doi.org/10.1016/S0031-9422(00)82682-5

17. Barbetti P, Fardella G, Chiappini I, Scarcia V, Furlani Candiani A New cytotoxic guaianolides and derivatives from Grosheimia macrocephala. Farmaco Ed Sci. 1985;40(10):755-69. https:// doi.org/10.1002/chin.198612322

18. Medeubaeva B, Adekenov SM. Cynaropicrin as a chemotaxonomic marker of plants of the genus Saussurea DC. In: Collection: Modern Trends in the Development of Health-preserving Technologies. Moscow: FSBSI VILAR; 2021. p. 352-6.

19. Zhang GG, Zheng YG. Gong Saussurea involucrata. Urumqi Xinjiang; 2013. p. 213.

20. Kaminsky IP. Sesquiterpene lactones of Centaurea scabiosa L. Chemical Study and Development of Analytical Methods: Abstract of Thesis; 2011. p. 22.

21. Youssef D, Frahm AW. Constituents of the Egyptian Centaurea scoparia II Guaianolides of the aerial parts. Planta Med. 1994;60(6):572-5. https://doi.org/10.1055/s-2006-959575. PMid: 17236083

22. Ohno N, Hirai H, Yoshioka Y. Cynaropicrin: A sesquiterpene lactone from Centaurea americana. Phytochemistry. 1973;12:221. https://doi.org/10.1016/s0031-9422(00)84659-2

23. Cho JY, Kim AR, Jung JH, Chun T, Rhee MN, Yoo ES. Cytotoxic and proapoptotic activities of cynaropicrin, a sesquiterpene lactone, on the viability of leukocyte cancer cell lines. Eur $J$ Pharmacol. 2004;492(2-3):85-94. https://doi.org/10.1016/j. ejphar.2004.03.027

PMid: 15178350

24. Emerdorfer F, Emerdorfer F, Bellato F, Noldin VF, CechinelFilho V, Yunes RA, et al. Antispasmodic activity of fractions and cynaropicrin from Cynara scolymus on guinea-pig ileum. Biol Pharm Bull. 2005;25(5):902-4. https://doi.org/10.1248/ bpb.28.902 PMid:15863902

25. Adekenov SM, Kupriyanov AM, Aituganov KA. Stocks of raw 
materials of Chartolepis intermedia Boiss., experience of cultivation and dynamics of localization of sesquiterpene lactone grossheimin. Plant Resour. 1991;3:67-73.

26. Vekhov VN, Lotova LI, Filin VR. Practical Course on the Anatomy and Morphology of Higher Plants. Moscow: MSU; 1980. p. 560.

27. Pakharukova MY, Shilov AG, Pirozhkova DS, Katokhin AV, Mordvinov VA. The first comprehensive study of praziquantel effects in vivo and in vitro on European liver fluke Opisthorchis felineus (Trematoda). Int J Antimicrob Agents. 2015;46(1):94-100. https://doi.org/10.1016/j. ijantimicag.2015.02.012

PMid:25862308

28. Khabriev RU. Guidelines for Experimental (Preclinical) Study of New Pharmacological Substances. Under the General Editorship of Corresponding Member of the Russian Academy of Medical Sciences. $2^{\text {nd }}$ ed. Moscow: OJSC Publishing House Medicine; 2005. p. 832.

29. Adekenov SM, Kishkentayeva AS, Atazhanova GA. Patent of RK 33713 Dated June 18, 2019. Extraction Method of Chartolepis intermedia Boiss; 2019.

Author Queries???

AQ3: Kindly review the sentence as it seems to be incomplete. 